Article

\title{
Establishment of an Improved Material-Drilling Power Model to Support Energy Management of Drilling Processes
}

\author{
Shun Jia ${ }^{1,2, *}$, Qingwen Yuan ${ }^{1, *}$, Wei Cai ${ }^{3}$, Qinghe Yuan ${ }^{2, *}$, Conghu Liu ${ }^{4}$, Jingxiang Lv 5 \\ and Zhongwei Zhang ${ }^{6}$ \\ 1 Department of Finance and Economics, Shandong University of Science and Technology, Jinan 250031, China \\ 2 Department of Industrial Engineering, Shandong University of Science and Technology, \\ Qingdao 266590, China \\ 3 College of Engineering and Technology, Southwest University, Chongqing 400715, China; \\ weicai@swu.edu.cn \\ 4 School of Mechanical and Electronic Engineering, Suzhou University, Suzhou 234000, China; \\ liuconghu@sjtu.edu.cn \\ 5 Key Laboratory of Contemporary Design and Integrated Manufacturing Technology, Ministry of Education, \\ Northwestern Polytechnical University, Xi'an 710072, China; youyilong@zju.edu.cn \\ 6 Department of Mechanical Manufacturing and Automation, Henan University of Technology, \\ Zhengzhou 450001, China; zzw_man@haut.edu.cn \\ * Correspondence: herojiashun@163.com or jiashun@sdust.edu.cn (S.J.); Tiger_yuan@163.com (Q.Y.); \\ yuan_qinghe@sina.com (Q.Y.); Tel.: +86-532-860-57044 (S.J.)
}

Received: 2 July 2018; Accepted: 31 July 2018; Published: 2 August 2018

check for updates

\begin{abstract}
Drilling processes, as some of the most widely used machining processes in the manufacturing industry, play an important role in manufacturing process energy-saving programs. However, research focus on energy modeling of drilling processes, especially for the modeling of material-drilling power, are really scarce. To bridge this gap, an improved material-drilling power model is proposed in this paper. The obtained material-drilling power model can improve the accuracy of the material-drilling power and lay a good foundation for energy modeling and optimization of drilling processes. Finally, experimental studies were carried out on an XHK-714F CNC machining center (Hangzhou HangJi Machine Tool Co., Ltd., Hangzhou, China) and a JTVM6540 CNC milling machine (Jinan Third Machine Tool Co., Ltd., Jinan, China). The results showed that predictive accuracies with the proposed model are generally higher than $96 \%$ for all the test cases.
\end{abstract}

Keywords: drilling process; material-drilling power; energy management

\section{Introduction}

Nowadays, climate change has become one of the most imperative topics [1]. Manufacturing processes are partially responsible for climate change due to the emissions generated as a result of energy consumption [2]. According to International Energy Outlook 2017 [3], the industrial sector (including manufacturing, mining, and so forth) accounts for about $50 \%$ of the world's energy use. World industrial sector energy use will increase by 18\% from 2015 to 2040, reaching 280 quadrillion British thermal units (Btu) by 2040, as shown in Figure 1 [3]. Manufacturing activities and production processes play a major role in industrial energy consumption, and are responsible for approximately $90 \%$ of the energy consumption in the industrial sector [4]. It has been pointed out that the manufacturing industry has a remarkable energy-saving potential [5]. More specifically, the worldwide manufacturing industries' energy-saving potential is estimated to be $20 \%$ through 
2050 [6]. Therefore, energy efficiency improvement of the manufacturing industry is identified as an important path for energy savings and climate change mitigation [1].

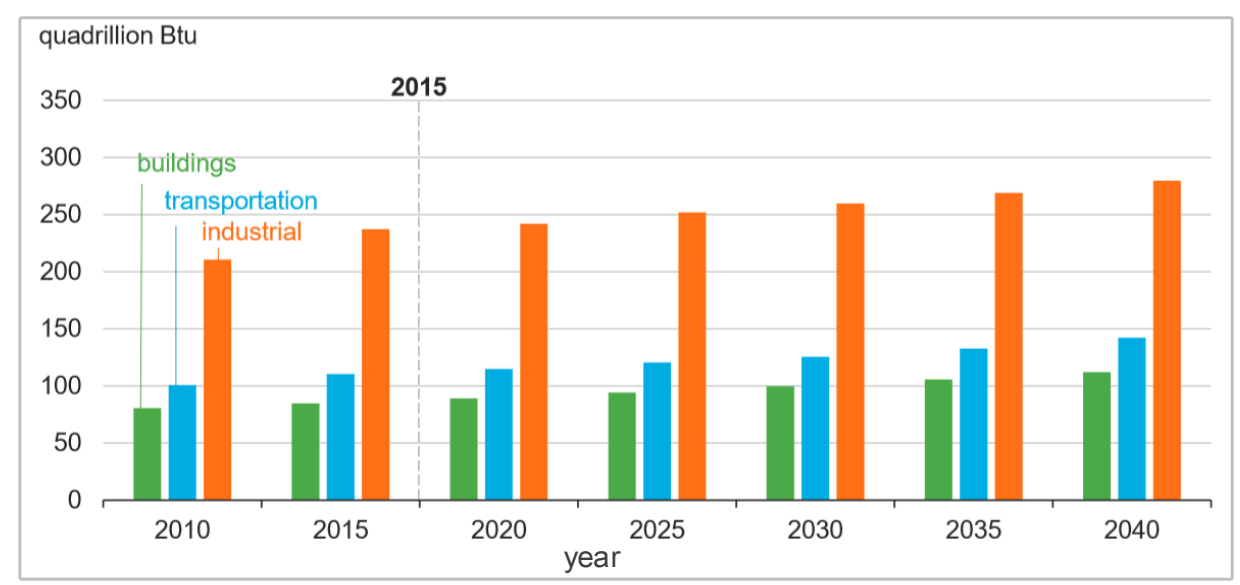

Figure 1. World energy consumption by end-use sector [3].

Manufacturing systems are complex entities with multiple subsystems that interact dynamically [7]. Machining systems, as some of the most important and widespread subsystems in manufacturing [8], play a key role in energy-saving for the manufacturing industry [9]. Moreover, a study conducted by Gutowski showed a very interesting result [10]: $\mathrm{CO}_{2}$ emissions of one computer numerical control (CNC) machine tool (22 kW spindle power) in one year are equivalent to the $\mathrm{CO}_{2}$ emissions of 61 SUVs (20.7 mpg, 12,000 miles/year). When it comes to $\mathrm{SO}_{2}$ and $\mathrm{NO}_{\mathrm{x}}$ emissions, as shown in Figure 2, one CNC machine tool is equivalent to 248 SUVs and 34 SUVs, respectively [10]. It can be seen that energy consumption and carbon emissions of machine tools are significant.

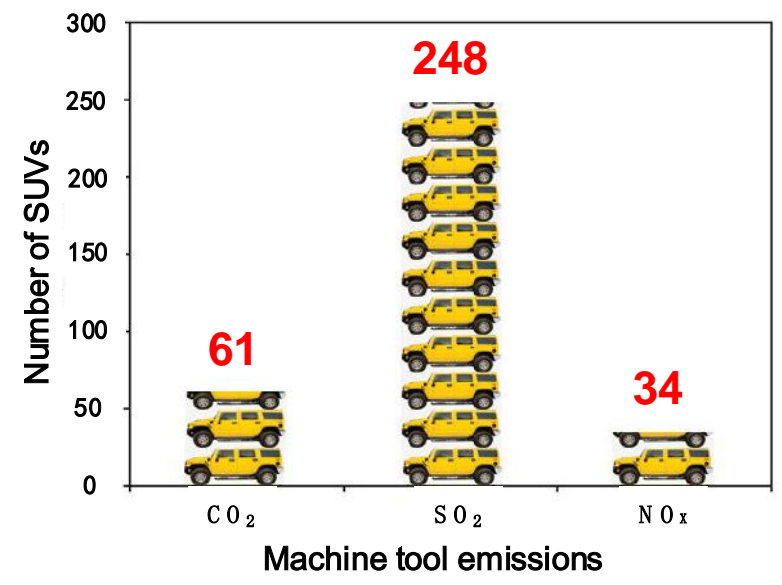

Figure 2. Machine tool emissions compared with SUVs [10].

Unfortunately, extensive studies have revealed that the energy efficiency of machine tools is generally less than $30 \%$ [11-13]. Therefore, the energy saving potential of machine tools is remarkable and energy efficiency improvement of machining processes has become a notable research area. Extensive existing studies have focused on energy modeling and energy savings of turning processes [14], milling processes [15,16], and grinding processes [17]. Drilling, as an important machining process, plays a significant role in the energy management of machining processes [18]. However, the energy modeling method focused on drilling processes, especially for the modeling of material-drilling power, has not been well studied [19]. The material-drilling power is the tool-tip cutting power, and is solely related to the material removal during drilling process [20]. 
The material-drilling power, as an important part of total drilling power, establishing its accurate power model is important for the energy modeling and energy optimization of the drilling processes. Up to now, research focused in particular on modeling of material-drilling power is really rare. To fill this gap, an improved material-drilling power model is established to support energy modeling and optimization of drilling processes. The advantages of this research are summarized as follows: (i) an improved material-drilling power model can be established for improving the prediction accuracy of drilling power; (ii) the obtained power model can lay a good foundation for energy modeling and optimization of drilling processes; (iii) material-drilling power, as a crucial part of total drilling power, the establishment of its power model can improve the transparency of energy consumption and help us to better understand energy characteristics during drilling processes.

\section{Literature Review}

Triggered by the necessity to improve the energy efficiency and environmental friendliness and reduce the energy-related costs of the manufacturing industry, extensive studies have been conducted in term of energy monitoring [21-23], energy modeling and carbon-emission evaluating [24-26], energy optimization and energy efficiency improvement [27-30], energy benchmarking [31,32], and solid waste reduction [33] of the manufacturing industry. Turning, milling, drilling and grinding processes are widely used in the manufacturing industry [8]. Unfortunately, a large number of existing studies have shown that the energy efficiencies of the above machining processes are generally less than $30 \%$ [11-13,34]. Therefore, extensive existing studies have been carried out focused specially on energy modeling and the energy saving potential of turning [35,36], milling [37-40], grinding [41,42], and sandcasting processes [43]. When it comes to drilling processes, the existing energy-related researches mainly focused on the micro-drilling processes [44], which are usually used for the manufacturing of the cooling holes in jet turbines blades, micro-holes in automotive fuel injection systems and so forth [45]. In order to help the operators decide on process parameters of micro-drilling process, an effective energy-saving strategy was devised for micro-drilling [46]. Moreover, for electrical discharge machining (EDM) drilling, as one of the most used micro-drilling processes, the specific electricity requirement is expressed as a function of the rate of material processed, as shown in Figure 3 [47]. However, the power required for EDM drilling in Figure 3 is an approximate value rather than an exact value, and the power is assumed to be 75\% of rated power for EDM drilling [47].

It is necessary to point out that the energy consumption characteristics of the micro-scale drilling are significantly different from those of the traditional drilling process. The energy involved in material removal in micro-scale machining is negligible compared to the energy consumed by the machine module [45]. For the traditional drilling process, the energy involved in material removal is much more important, and the material-drilling power is an important part of the total drilling power. However, the power model of the drilling process, especially for the material-drilling power, has not been well studied. The theoretical material-drilling power can be calculated based on the manual of machining process $[48,49]$. However, the actual material-cutting power includes not only the theoretical material-drilling power but also the additional loss power, which is involved with the drilling cutters, drilling parameters, machine tools and workpiece [19]. Research specially focused on the material-drilling power is really rare. In our previous study [19] we tried to establish a simple material-drilling power model, however, the accuracy and the effectiveness of the material-drilling power model needs to be further improved. Consequently, an improved material-drilling power model is proposed in this paper to improve the material-drilling power predictive accuracy. The outcomes of this study can improve the transparency of energy consumption and help us to better understand the energy characteristics of drilling processes. 


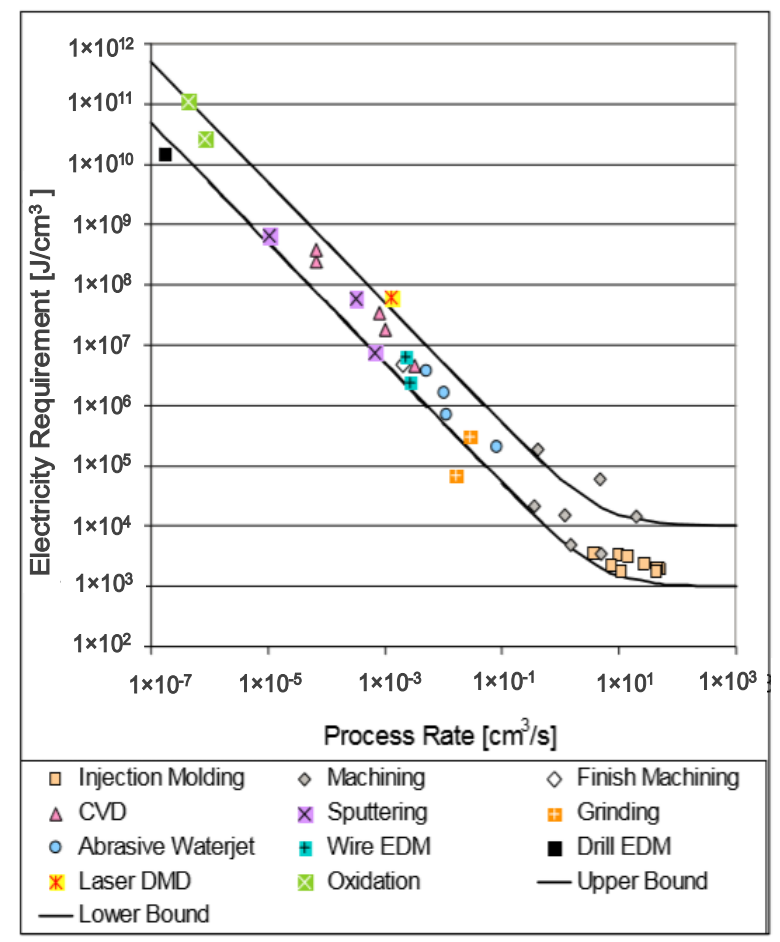

Figure 3. Specific electricity requirements for various manufacturing processes as a function of the rate of material processed [47].

\section{Methodology}

\subsection{Composition of Material-Drilling Power}

The material-drilling power is defined as the tool-tip cutting power during drilling process, which is solely related to the material removal [20]. The material-drilling power $\left(P_{m d}\right)$ is an important part of total drilling power $\left(P_{T D}\right)$ during material cutting. As shown in Figure 4 . The total drilling power is composed of power of standby operation $\left(P_{s o}\right)$, power of spraying cutting flood $\left(P_{s f}\right)$, power of spindle rotation $\left(P_{s r}\right)$, power of $Z$-axis feeding $\left(P_{z f}\right)$ and power of material-drilling $\left(P_{m d}\right)$. The power of standby operation $P_{s o}$ is the power consumed by the various basic modules (i.e., NC (Numerical control) system, display, fans, etc.) to ensure the operational readiness. The power of spraying cutting flood $P_{s f}$ is related to the cooling device, which is turned on during drilling processes. The power of spindle rotation $P_{s r}$ refers to the power needed to guarantee the rotation of the spindle. The power of $Z$-axis feeding $P_{z f}$ is the power consumed by the feed driving system during $Z$-axis feeding. The power models of standby operating, spraying cutting flood, spindle rotating and $Z$-axis feeding have been researched in our previous work $[19,20]$, so the establishment of the above power models $\left(P_{s o}, P_{s f}\right.$, $P_{s r}$ and $\left.P_{z f}\right)$ are out of the scope of this paper while the establishment of the material-drilling power model $\left(P_{m d}\right)$ is the focus in this paper. Moreover, the standby operating power, spraying cutting flood power, spindle rotating power, $Z$-axis feeding power constitute the air cutting power $\left(P_{\text {air }}\right)$, which is the power consumed while the cutter approaching the workpiece with the designed tool path and cutting parameters before actual material removal [35]. Therefore, the material-drilling power $P_{m d}$ can be obtained by subtracting the air cutting power $P_{\text {air }}$ from the total drilling power $P_{T D}$. More specifically, the material-drilling power can further be divided into two parts: theoretical cutting power $\left(P_{\text {Tcut }}\right)$ and additional loss power $\left(P_{\text {Aloss }}\right)$. The detailed modeling approach will be discussed in the next subsection. 


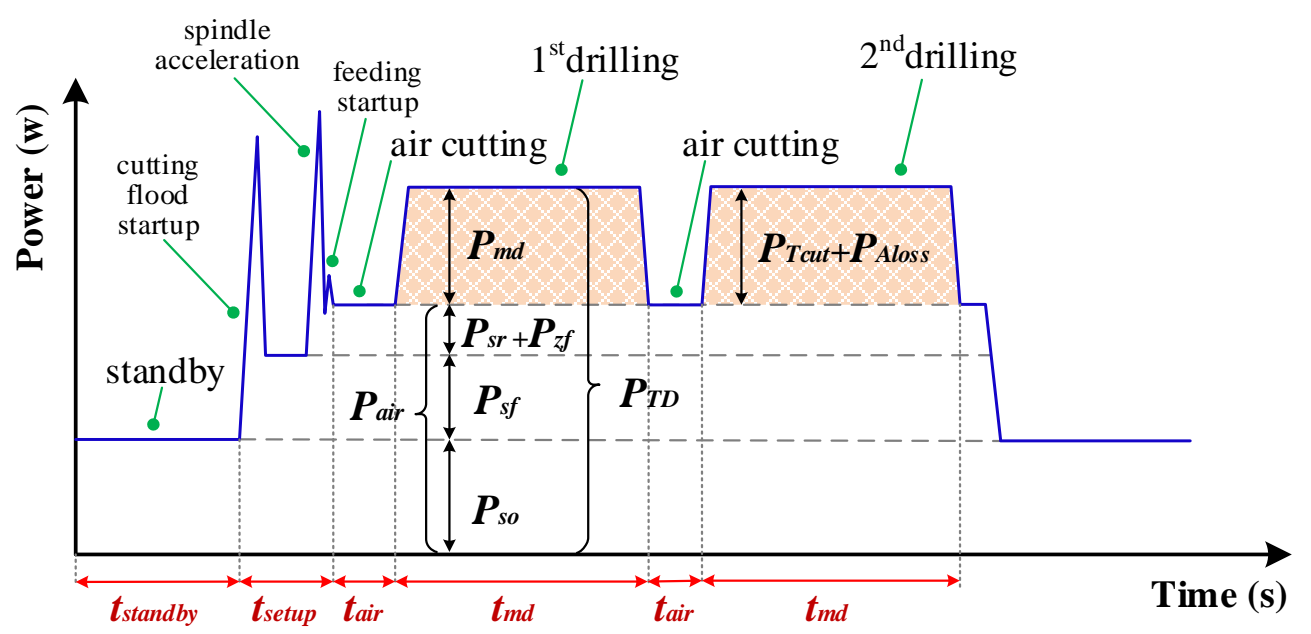

Figure 4. Power profile of a machine tool during drilling processes.

\subsection{Improved Material-Drilling Power Model}

As mentioned above, the material-drilling power can be divided into two parts: (a) theoretical cutting power $\left(P_{T c u t}\right)$, and $(\mathrm{b})$ additional loss power $\left(P_{\text {Aloss }}\right)$. Hence, the material-drilling power can be expressed as:

$$
P_{m d}=P_{\text {Tcut }}+P_{\text {Aloss }}
$$

where $P_{m d}$ is material-drilling power, $\mathrm{W} ; P_{\text {Tcut }}$ is theoretical drilling power, $\mathrm{W} ; P_{\text {Aloss }}$ is additional loss power, $\mathrm{W}$.

The theoretical drilling power $P_{\text {Tcut }}$ is the cutting power of the tool tip acting on the workpiece, which is the theoretical and minimum power needed to ensure the material removal, and is related to the cutter material, workpiece material and cutting parameters. In addition, the additional loss power $P_{\text {Aloss }}$ is the power loss of the machine tool caused by the cutting load on the cutting tool. The value of the additional loss power depends on the structure and energy characteristic of machine tool. Moreover, the additional loss power $P_{\text {Aloss }}$ can be calculated as a linear function of the theoretical cutting power $P_{\text {Tcut }}$ [50]. Therefore, the additional loss power can be expressed as:

$$
P_{\text {Aloss }}=\alpha_{0} P_{\text {Tcut }}
$$

where $\alpha_{0}$ is additional power loss coefficient.

According to Equations (1) and (2), the material-drilling power can further be calculated as:

$$
P_{m d}=P_{\text {Tcut }}+P_{\text {Aloss }}=P_{\text {Tcut }}+\alpha_{0} P_{\text {Tcut }}=\left(1+\alpha_{0}\right) P_{\text {Tcut }}
$$

More specifically, the theoretical drilling power can be computed as [48,49]:

$$
P_{\text {Tcut }}=M \omega=\left(C_{M} d^{z_{M}} f^{y_{M}} k_{M}\right) \frac{2 \pi n}{60}
$$

where $M$ is drilling torque, $\mathrm{N} \cdot \mathrm{m} ; \omega$ is rotation angular velocity of the cutting tool, $\mathrm{rad} / \mathrm{s} ; C_{M}$ and $k_{M}$ are correction coefficients related to the cutter material, workpiece material and cutting conditions; $d$ is drill diameter, $\mathrm{mm} ; z_{M}$ is exponent of the drill diameter; $f$ is feed rate, $\mathrm{mm} / \mathrm{r} ; y_{M}$ is exponent of the feed rate; $n$ is spindle speed, $\mathrm{r} / \mathrm{min}$. The theoretical drilling power is the minimum power to ensure the material removal. However, the additional loss power of machine tool caused by the cutting load was not considered in the theoretical drilling power. Therefore, the theoretical drilling power is not machine tool dependent. 
According to Equations (3) and (4), the material-drilling power can be written as:

$$
P_{m d}=\left(1+\alpha_{0}\right) P_{T c u t}=\left(C_{M} d^{z_{M}} f^{y_{M}} k_{M}\right) \frac{2 \pi n}{60}=\frac{\pi\left(1+\alpha_{0}\right) C_{M} k_{M}}{30} d^{z_{M}} f^{y_{M} n}
$$

For a given combination of machine tool, workpiece material and cutting tool, the values of the $\frac{\pi\left(1+\alpha_{0}\right) C_{M} k_{M}}{30}, z_{M}$ and $y_{M}$ are constant. Therefore, the material-drilling power can also be expressed as:

$$
P_{m d}=\lambda_{D 1} d^{\alpha_{D 1}} f^{\beta_{D 1} n}
$$

where $\lambda_{D 1}, \alpha_{D 1}$ and $\beta_{D 1}$ are constants and set $\lambda_{D 1}=\frac{\pi\left(1+\alpha_{0}\right) C_{M} k_{M}}{30}, \alpha_{D 1}=z_{M}$ and $\beta_{D 1}=y_{M}$. It can be seen that the material-drilling power $P_{m d}$ is a function of drill diameter, feed rate and spindle speed. In addition, the exponents of the drill diameter, feed rate and spindle speed are $\alpha_{D 1}, \beta_{D 1}$ and 1 , respectively.

According to the experimental research of literature [51], the material-drilling power was expressed as the function of feed rate $(f)$ and cutting speed $\left(v_{c}\right)$.

$$
P_{m d}=C_{F} f^{x} v_{c}^{y}
$$

where $C_{F}$ is correction coefficient; $f$ is feed rate, $\mathrm{mm} / \mathrm{r} ; v_{c}$ is cutting speed, $\mathrm{m} / \mathrm{min} ; x$ is exponent of the feed rate; $y$ is exponent of the cutting speed.

For drilling process, the cutting speed can be calculated as:

$$
v_{c}=\frac{n \pi d}{1000}
$$

where $n$ is spindle speed, $\mathrm{r} / \mathrm{min} ; d$ is drill diameter, $\mathrm{mm}$.

According to Equations (7) and (8), the material-drilling power can further written as:

$$
P_{m d}=C_{F} f^{x}\left(\frac{n \pi d}{1000}\right)^{y}=C_{F}\left(\frac{\pi}{1000}\right)^{y} d^{y} f^{x} n^{y}
$$

Similarly, $C_{F}\left(\frac{\pi}{1000}\right)^{y}, x$ and $y$ are constants. Consequently, the material-drilling power is also a function of drill diameter, feed rate and spindle speed. However, in this model, the value of exponent of the spindle speed is $y$ (the value of $y$ may not be 1 , and $y=0.77$ was obtained for the given combination of machine tool, cutter and workpiece in [51]), and is equal to the exponent of the drill diameter. Based on the preliminary experimental data of our research group, the changing trend of material-drilling power with respect to drill diameter and spindle speed is shown in Figure 5. It can be seen that the material-drilling power $P_{m d}$ increases with the increase of the spindle speed $n$ and drill diameter $d$. However, the degree of the influence is different. Thus, the exponent of the spindle speed and the drill diameter should be different. That is to say, the exponent of the spindle speed in the material-drilling power model will be a value that is not necessarily equal to 1 and different from the exponent of the drill diameter. 


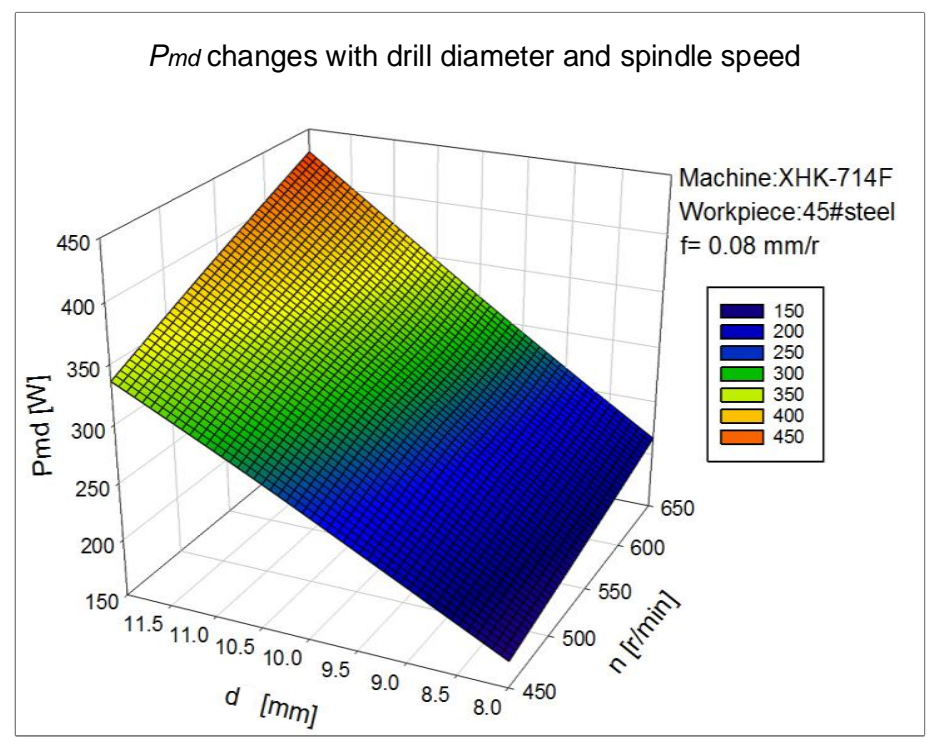

Figure 5. $P_{m d}$ changes with respect to drill diameter and spindle speed $(f=0.08 \mathrm{~mm} / \mathrm{r})$.

According to the above analysis, an improved material-drilling power model can be proposed on the basis of Equation (6). The improved material-drilling power model is written as:

$$
P_{m d}=\lambda_{D 2} d^{\alpha} f^{\beta_{D 2}} n^{\gamma_{D 2}}
$$

where $\lambda_{D 2}$ is the coefficient of the improved material-drilling power model; $d$ is the drill diameter, mm; $\alpha_{D 2}$ is the exponent of the drill diameter in the improved power model; $f$ is feed rate, $\mathrm{mm} / \mathrm{r} ; \beta_{D 2}$ is exponent of the feed rate in the improved power model; $n$ is spindle speed, $\mathrm{r} / \mathrm{min} ; \gamma_{D 2}$ is exponent of the spindle speed in the improved power model. $\lambda_{D 2}, \alpha_{D 2}, \beta_{D 2}$, and $\gamma_{D 2}$ are all constants and the values of the above constants are determined by the combination of machine tool, cutter material and workpiece material, which are extremely difficult to be obtained by theoretical analysis. Thus, the values of these constants will be obtained by pre-experiments and statistical analysis. The proposed material-drilling power model considers both the theoretical drilling power and the additional loss power. The additional loss power depends on the structure and energy characteristic of machine tool. Consequently, the proposed material-drilling power model is machine tool dependent. It is necessary to point out that the limitation of the proposed model is that the coefficients in the model will be different under different combinations of machine tools, cutting tools, and workpiece materials. Consequently, the pre-experiments and statistical analysis need to be repeated to obtained the model coefficients when it applies to other combination of machine tool, cutting tool, and workpiece material.

\section{Experimental Study}

\subsection{Design of Experiments}

In order to show the validity of the improved material-drilling power model, experimental studies were conducted on a XHK-714F CNC machining center (Hangzhou HangJi Machine Tool Co., Ltd., Hangzhou, China) and a JTVM6540 CNC milling machine (Jinan Third Machine Tool Co., Ltd., Jinan, China). The rated power of the spindle motor of the XHK-714F CNC machining center is $7.5 \mathrm{~kW}$ and the rapid-positioning speeds of $X, Y$, and $Z$-axis are 12,000, 12,000, and 10,000 $\mathrm{mm} / \mathrm{min}$, respectively. For the JTVM6540 CNC milling machine, the rated power of the spindle motor is $4.0 \mathrm{~kW}$ and the rapid-positioning speeds of $X, Y$, and Z-axis are all $6000 \mathrm{~mm} / \mathrm{min}$. Based on to the improved material-drilling power model, the experimental design parameters are selected as the drill diameter $d$, feed rate $f$, and spindle speed $n$. According to the machining process manual, the recommended 
cutting parameters of the cutter, and the machine tool performance $[19,48,49]$, the drilling parameters and their levels were determined, as shown in Table 1.

Table 1. Drilling parameters and their levels.

\begin{tabular}{cccc}
\hline Variables & Level 1 & Level 2 & Level 3 \\
\hline Drill diameter $d(\mathrm{~mm})$ & 8 & 10 & 12 \\
Feed rate $f(\mathrm{~mm} / \mathrm{r})$ & 0.06 & 0.08 & 0.10 \\
Spindle speed $n(\mathrm{r} / \mathrm{min})$ & 450 & 550 & 650 \\
\hline
\end{tabular}

Based on the number of the drilling parameters and levels of the experiment, a L27 $\left(3^{13}\right)$ orthogonal table was used to arrange the experiments. The selected cutter is a parallel shank twist drill manufactured by NACHI Company (Tokyo, Japan) and the drill point angle is $118^{\circ}$. The material of the workpiece for experiments is $45 \#$ steel and the shape of the workpiece is $150 \times 150 \times 30 \mathrm{~mm}$. Moreover, the drilling condition is wet cutting and the ordinary water base emulsion was used as the cutting fluid. In order to measure the material-drilling power during experiments, a power-energy acquisition system has been established by our research group [36]. As shown in Figure 6, the power-energy acquisition system is mainly composed of one compactDAQ crate, two NI-9215 (National Instruments, Austin, TX, USA) data collection cards, one sensor power supply, three voltage sensors, and three current sensors. The experiments were conducted on the XHK-714F CNC machining center and JTVM6540 CNC milling machine, respectively. Simultaneously, the power-energy acquisition system was connected with the machine tool and the power and energy data during experiments were recorded once every $0.1 \mathrm{~s}$.

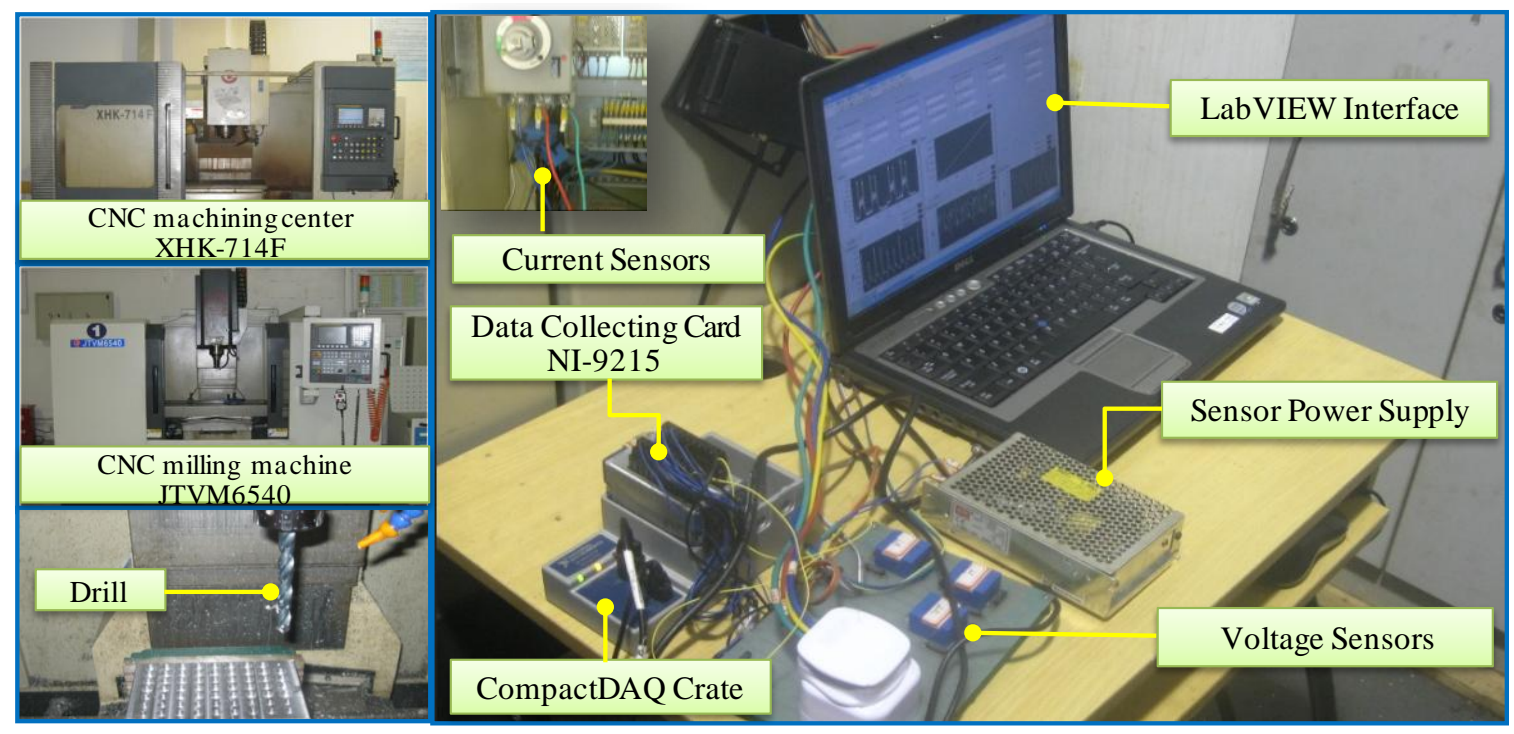

Figure 6. Experimental setup of power-energy acquisition system.

\subsection{Results and Discussion}

The values of material-drilling power during the experiments can be obtained by using the power-energy acquisition system shown in Figure 6. The measured material-drilling power under different combinations of drilling parameters for the XHK-714F CNC machining center and JTVM654 $\mathrm{CNC}$ milling machine are shown in Table 2. In order to clearly display the characteristics and trends of the material-drilling power, the measured material-drilling power values for the researched machine tools are also shown in Figure 7. It can be seen that the material-drilling power of the XHK-714F CNC machining center is larger than the JTVM654 CNC milling machine under the same combination of 
the drilling parameters. The main reason for this is that the rated power of spindle motor $(7.5 \mathrm{~kW})$ of the XHK-714F CNC machining center is far greater than the rated power of spindle motor $(4.0 \mathrm{~kW})$ of the JTVM654 CNC milling machine. The material-drilling power is influenced by the additional loss power, which is related with the rated power of the spindle motor.

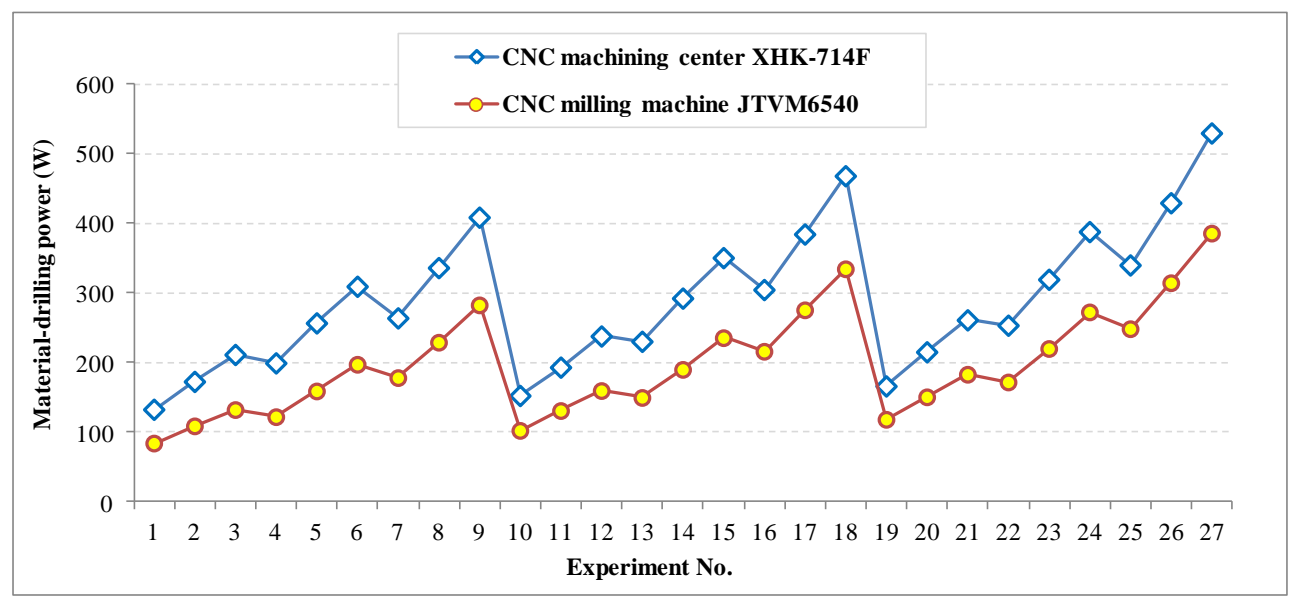

Figure 7. Comparison of the measured material-drilling power for the researched machine tools.

Table 2. Measured material-drilling power under different combinations of drilling parameters for the XHK-714F CNC machining center and JTVM654 CNC milling machine.

\begin{tabular}{|c|c|c|c|c|c|}
\hline No. & $\begin{array}{l}\text { Drill Diameter } \\
\quad d(\mathrm{~mm})\end{array}$ & $\begin{array}{c}\text { Feed Rate } \\
f(\mathrm{~mm} / \mathrm{r})\end{array}$ & $\begin{array}{l}\text { Spindle Speed } \\
n(\mathrm{r} / \mathrm{min})\end{array}$ & $\begin{array}{l}\text { Material-Drilling } \\
\text { Power } P_{m d}{ }^{1}(\mathrm{~W})\end{array}$ & $\begin{array}{l}\text { Material-Drilling } \\
\text { Power } P_{m d}{ }^{2} \text { (W) }\end{array}$ \\
\hline 1 & 8 & 0.06 & 450 & 133.0 & 84.5 \\
\hline 2 & 8 & 0.08 & 450 & 173.0 & 109.2 \\
\hline 3 & 8 & 0.10 & 450 & 211.7 & 132.6 \\
\hline 4 & 10 & 0.06 & 450 & 199.6 & 122.4 \\
\hline 5 & 10 & 0.08 & 450 & 257.0 & 159.3 \\
\hline 6 & 10 & 0.10 & 450 & 309.6 & 197.6 \\
\hline 7 & 12 & 0.06 & 450 & 264.2 & 178.5 \\
\hline 8 & 12 & 0.08 & 450 & 336.4 & 229.3 \\
\hline 9 & 12 & 0.10 & 450 & 408.8 & 282.9 \\
\hline 10 & 8 & 0.06 & 550 & 152.8 & 102.7 \\
\hline 11 & 8 & 0.08 & 550 & 193.5 & 131.2 \\
\hline 12 & 8 & 0.10 & 550 & 238.2 & 159.9 \\
\hline 13 & 10 & 0.06 & 550 & 230.6 & 150.0 \\
\hline 14 & 10 & 0.08 & 550 & 292.6 & 190.3 \\
\hline 15 & 10 & 0.10 & 550 & 350.7 & 235.8 \\
\hline 16 & 12 & 0.06 & 550 & 304.9 & 216.3 \\
\hline 17 & 12 & 0.08 & 550 & 384.6 & 275.8 \\
\hline 18 & 12 & 0.10 & 550 & 468.3 & 334.7 \\
\hline 19 & 8 & 0.06 & 650 & 166.5 & 118.6 \\
\hline 20 & 8 & 0.08 & 650 & 215.5 & 150.9 \\
\hline 21 & 8 & 0.10 & 650 & 261.4 & 183.3 \\
\hline 22 & 10 & 0.06 & 650 & 253.7 & 172.2 \\
\hline 23 & 10 & 0.08 & 650 & 319.6 & 220.3 \\
\hline 24 & 10 & 0.10 & 650 & 388.1 & 272.8 \\
\hline 25 & 12 & 0.06 & 650 & 340.2 & 248.7 \\
\hline 26 & 12 & 0.08 & 650 & 429.5 & 314.7 \\
\hline 27 & 12 & 0.10 & 650 & 529.7 & 385.9 \\
\hline
\end{tabular}

${ }_{1}^{1}$ Measured material-drilling power for the XHK-714F CNC machining center. ${ }^{2}$ Measured material-drilling power for the JTVM654 CNC milling machine.

According to the above measured material-drilling power values, the curve fitting was carried out according to Equations (6) and (10) with the Origin8. $0^{\circledR}$ Software (OriginLab Corporation, Northampton, MA, USA). The curve fitting results for material-drilling power of the XHK-714F 
CNC machining center are shown in Table 3. In addition, the Analysis Of Variance (ANOVA) for the material-drilling power of the XHK-714F CNC machining center is shown in Table 4.

Table 3. Curve fitting results for material-drilling power of the XHK-714F CNC machining center.

\begin{tabular}{|c|c|c|c|c|c|c|}
\hline Model & Coefficients & Value & Standard Error & $t$-Value & Prob $>|t|$ & Statistics \\
\hline \multirow{3}{*}{ Model A ${ }^{1}$} & $\lambda_{D 1}$ & 0.095 & 0.021 & 4.530 & \multirow{3}{*}{$\begin{array}{c}1.371 \times 10^{-4} \\
0 \\
5.462 \times \\
10^{-14}\end{array}$} & \multirow{3}{*}{$\begin{array}{c}\text { R-Square(COD) } \\
0.974\end{array}$} \\
\hline & $\alpha_{D 1}$ & 1.675 & 0.072 & 23.153 & & \\
\hline & $\beta_{D 1}$ & 0.856 & 0.055 & 15.479 & & \\
\hline \multirow{4}{*}{ Model B 2} & $\lambda_{D 2}$ & 0.866 & 0.107 & 8.095 & $3.499 \times 10^{-8}$ & R-Square(COD) \\
\hline & $\alpha_{D 2}$ & 1.673 & 0.018 & 94.531 & 0 & \multirow[t]{3}{*}{0.998} \\
\hline & $\beta_{D 2}$ & 0.856 & 0.014 & 63.256 & 0 & \\
\hline & $\gamma_{D 2}$ & 0.652 & 0.017 & 37.493 & 0 & \\
\hline
\end{tabular}

Table 4. ANOVA for material-drilling power of the XHK-714F CNC machining center.

\begin{tabular}{|c|c|c|c|c|c|c|}
\hline Model & Items & DF & Sum of Squares & Mean Square & F Value & Prob $>$ F \\
\hline \multirow{4}{*}{ Model A ${ }^{1}$} & Regression & 3 & $2.517 \times 10^{6}$ & $839,115.840$ & 2951.245 & 0 \\
\hline & Residual & 24 & 6823.826 & 284.326 & & \\
\hline & $\begin{array}{c}\text { Uncorrected } \\
\text { Total }\end{array}$ & 27 & $2.524 \times 10^{6}$ & & & \\
\hline & $\begin{array}{l}\text { Corrected } \\
\text { Total }\end{array}$ & 26 & $262,952.539$ & & & \\
\hline \multirow{4}{*}{ Model B 2} & Regression & 4 & $2.524 \times 10^{6}$ & $630,944.704$ & $36,969.728$ & 0 \\
\hline & Residual & 23 & 392.530 & 17.067 & & \\
\hline & $\begin{array}{c}\text { Uncorrected } \\
\text { Total }\end{array}$ & 27 & $2.524 \times 10^{6}$ & & & \\
\hline & $\begin{array}{l}\text { Corrected } \\
\text { Total }\end{array}$ & 26 & $262,952.539$ & & & \\
\hline
\end{tabular}

${ }^{1}$ Empirical model with the equation $P_{m d}=\lambda_{D 1} \cdot d^{\alpha}{ }^{\alpha} \cdot f^{\beta_{D 1}} \cdot n .{ }^{2}$ Improved model with the equation $P_{m d}=\lambda_{D 2} \cdot d^{\alpha_{D 2}} \cdot f^{\beta_{D 2}} \cdot n^{\gamma_{D 2}}$.

According to the fitting results of Table 3 , the coefficients and exponents in the traditional empirical model of material-drilling power are as follows: $\lambda_{D 1}=0.095, \alpha_{D 1}=1.675$, and $\beta_{D 1}=0.856$. Therefore, the traditional empirical model of material-drilling power of the $\mathrm{CNC}$ machining center XHK-714F can be expressed as:

$$
P_{m d}(\mathrm{XHK}-714 \mathrm{~F})=0.095 d^{1.675} \times f^{0.856} \times n
$$

Similarly, the coefficients and exponents in the improved model of material-drilling power are obtained according to Table 3 . The values are shown as follows: $\lambda_{D 2}=0.866, \alpha_{D 2}=1.673, \beta_{D 2}=0.856$, and $\gamma_{D 2}=0.652$. Consequently, the improved material-drilling power model of the CNC machining center XHK-714F can be written as:

$$
P_{m d}(\mathrm{XHK}-714 \mathrm{~F})=0.866 d^{1.673} \times f^{0.856} \times n^{0.652}
$$

According to the ANOVA table for material-drilling power of the CNC machining center XHK-714F (Table 4), the P value for the model A and model B are both very small (Prob $=0<0.05,95 \%$ confidence level), which indicates the strong correlation between $P_{m d}$ (material-drilling power) and the drilling parameter $d$ (cutter diameter), $f$ (feed rate) and $n$ (spindle speed). In addition, the R-Square value can be obtained according to Table 3, R-Square $=0.974$ for the model A and R-Square $=0.998$ for the model B. The closer the R-Square value is to 1 , the better the fitting result is. Therefore, the model B (improved material-drilling power model) could describe the material-drilling power under various 
combinations of cutter diameter, feed rate and spindle speed better than the model A (traditional empirical material-drilling power model).

In order to further show the validity of the improved material-drilling power model, the experimental data obtained on the JTVM654 CNC milling machine were analyzed. Similarly, the curve fitting was conducted according to Equations (6) and (10) with the Origin8.0 $0^{\circledR}$ Software. The curve fitting results for material-drilling power of the JTVM654 CNC milling machine were shown in Table 5. In addition, the Analysis Of Variance (ANOVA) for material-drilling power of the JTVM654 CNC milling machine is shown in Table 6.

Table 5. Curve fitting results for material-drilling power of the JTVM6540 CNC milling machine.

\begin{tabular}{|c|c|c|c|c|c|c|}
\hline Model & Coefficients & Value & Standard Error & $t$-Value & Prob $>|t|$ & Statistics \\
\hline \multirow{3}{*}{ Model A ${ }^{1}$} & $\lambda_{D 1}$ & 0.045 & 0.004 & 10.220 & $\begin{array}{c}3.211 \times \\
10^{-10}\end{array}$ & $\begin{array}{c}\text { R-Square } \\
\text { (COD) }\end{array}$ \\
\hline & $\alpha_{D 1}$ & 1.860 & 0.032 & 57.680 & 0 & 0.996 \\
\hline & $\beta_{D 1}$ & 0.881 & 0.024 & 36.491 & 0 & \\
\hline \multirow{4}{*}{ Model B ${ }^{2}$} & $\lambda_{D 2}$ & 0.103 & 0.013 & 7.818 & $6.349 \times 10^{-8}$ & $\begin{array}{c}\text { R-Square } \\
\text { (COD) }\end{array}$ \\
\hline & $\alpha_{D 2}$ & 1.860 & 0.019 & 100.424 & 0 & 0.999 \\
\hline & $\beta_{D 2}$ & 0.881 & 0.014 & 63.542 & 0 & \\
\hline & $\gamma_{D 2}$ & 0.870 & 0.018 & 48.645 & 0 & \\
\hline
\end{tabular}

${ }^{1}$ Empirical model with the equation $P_{m d}=\lambda_{D 1} \cdot d^{\alpha_{D 1}} \cdot f^{\beta_{D 1}} \cdot n .{ }^{2}$ Improved model with the equation $P_{m d}=\lambda_{D 2} \cdot d^{\alpha_{D 2}} \cdot f^{\beta_{D 2}} \cdot n^{\gamma_{D 2}}$.

Table 6. ANOVA for material-drilling power of the JTVM6540 CNC milling machine.

\begin{tabular}{|c|c|c|c|c|c|c|}
\hline Model & Items & DF & Sum of Squares & Mean Square & F Value & Prob $>$ F \\
\hline \multirow{4}{*}{ Model A ${ }^{1}$} & Regression & 3 & $1.215 \times 10^{6}$ & $405,086.248$ & $15,596.363$ & 0 \\
\hline & Residual & 24 & 623.355 & 25.973 & & \\
\hline & $\begin{array}{c}\text { Uncorrected } \\
\text { Total }\end{array}$ & 27 & $1.216 \times 10^{6}$ & & & \\
\hline & $\begin{array}{l}\text { Corrected } \\
\text { Total }\end{array}$ & 26 & $151,650.362$ & & & \\
\hline \multirow{4}{*}{ Model B 2} & Regression & 4 & $1.216 \times 10^{6}$ & $303,921.230$ & $35,451.033$ & 0 \\
\hline & Residual & 23 & 197.179 & 8.573 & & \\
\hline & $\begin{array}{c}\text { Uncorrected } \\
\text { Total }\end{array}$ & 27 & $1.216 \times 10^{6}$ & & & \\
\hline & $\begin{array}{c}\text { Corrected } \\
\text { Total }\end{array}$ & 26 & $151,650.362$ & & & \\
\hline
\end{tabular}

${ }^{1}$ Empirical model with the equation $P_{m d}=\lambda_{D 1} \cdot d^{\alpha_{D 1}} \cdot f^{\beta_{D 1}} \cdot n .{ }^{2}$ Improved model with the equation $P_{m d}=$ $\lambda_{D 2} \cdot d^{\alpha} \alpha^{\alpha} \cdot f^{\beta_{D 2}} \cdot n^{\gamma_{D 2}}$.

According to the fitting results of Table 5, the coefficients and exponents in the traditional empirical model of material-drilling power are as follows: $\lambda_{D 1}=0.045, \alpha_{D 1}=1.860$, and $\beta_{D 1}=0.881$. Therefore, the traditional empirical model of material-drilling power of the JTVM6540 CNC milling machine can be expressed as:

$$
P_{m d}(\text { JTVM6540 })=0.045 d^{1.860} \times f^{0.881} \times n
$$

Similarly, the coefficients and exponents in the improved model of material-drilling power are obtained according to Table 5. The values are shown as follows: $\lambda_{D 2}=0.103, \alpha_{D 2}=1.860, \beta_{D 2}=0.881$, and $\gamma_{D 2}=0.870$. Consequently, the improved material-drilling power model of the JTVM6540 CNC milling machine can be written as:

$$
P_{m d}(\text { JTVM6540 })=0.103 d^{1.860} \times f^{0.881} \times n^{0.870}
$$


According to the ANOVA table for material-drilling power of the JTVM654 CNC milling machine (Table 6 ), the $P$ value for the model $A$ and model $B$ are both very small (Prob $=0<0.05,95 \%$ confidence level), which indicates the strong correlation between $P_{m d}$ (material-drilling power) and the drilling parameter $d$ (cutter diameter), $f$ (feed rate) and $n$ (spindle speed). In addition, the R-Square value can be obtained according to Table 5, R-Square $=0.996$ for the model A and R-Square $=0.999$ for the model B. The closer the R-Square value is to 1, the better the fitting result is. Therefore, for the JTVM654 CNC milling machine the model B (improved material-drilling power model) is also better than the model A (traditional empirical material-drilling power model) for describing the material-drilling power under various combinations of cutter diameter, feed rate and spindle speed.

In order to show the effectiveness of the improved material-drilling power model, four random tests were selected and the detailed drilling parameters of the four tests are listed in Table 7 . In order to make the experiments more scientific and more credible, the four test experiments were carried out on both the XHK-714F CNC machining center and the JTVM6540 CNC milling machine. The material-drilling power during drilling process of the researched machine tool were measured by the power-energy acquisition system shown in Figure 6. The predicted material-drilling power values were obtained with both the traditional empirical model and the improved power model in this paper, as shown in Table 7.

Table 7. The accuracy of the developed material-drilling power models of four test cases.

\begin{tabular}{|c|c|c|c|c|c|c|c|c|}
\hline \multirow{2}{*}{ Items } & \multicolumn{4}{|c|}{ CNC Machining Center XHK-714F } & \multicolumn{4}{|c|}{ CNC Milling Machine JTVM6540 } \\
\hline & Test 1 & Test 2 & Test 3 & Test 4 & Test 1 & Test 2 & Test 3 & Test 4 \\
\hline Drill diameter (mm) & 12 & 10 & 10 & 8 & 12 & 10 & 10 & 8 \\
\hline Feed rate $(\mathrm{mm} / \mathrm{r})$ & 0.07 & 0.08 & 0.07 & 0.09 & 0.07 & 0.08 & 0.07 & 0.09 \\
\hline Spindle speed (r/min) & 460 & 580 & 540 & 640 & 460 & 580 & 540 & 640 \\
\hline Measured power (W) & 319.8 & 298.1 & 256.8 & 236.5 & 213.8 & 200.8 & 170.6 & 166.4 \\
\hline Predicted P with model A ${ }^{1}(\mathrm{~W})$ & 288.1 & 300.1 & 249.2 & 252.0 & 202.2 & 204.3 & 169.1 & 165.1 \\
\hline Predicted P with model B ${ }^{2}(\mathrm{~W})$ & 309.4 & 297.4 & 253.2 & 241.5 & 208.6 & 204.5 & 170.8 & 163.2 \\
\hline Accuracy of model A & $90.1 \%$ & $99.3 \%$ & $97.0 \%$ & $93.4 \%$ & $94.6 \%$ & $98.3 \%$ & $99.1 \%$ & $99.2 \%$ \\
\hline Accuracy of model B & $96.7 \%$ & $99.8 \%$ & $98.6 \%$ & $97.9 \%$ & $97.6 \%$ & $98.2 \%$ & $99.9 \%$ & $98.1 \%$ \\
\hline
\end{tabular}

The comparison of accuracy of the traditional empirical model (model A) and the improved power model in this paper (model B) for the researched machine tools (XHK-714F CNC machining center and JTVM6540 CNC milling machine) are shown in Figures 8 and 9. It can be seen that the improved material-drilling power model can improve the prediction accuracy of the material-drilling power. As shown in Figure 8, the prediction accuracies of Test 1-Test 4 are 96.7\%, 99.8\%, 98.6\%, and 97.9\% for the XHK-714F CNC machining center. The prediction accuracies are improved by $6.6 \%, 0.5 \%$, $1.6 \%$, and $4.5 \%$ compared with the traditional empirical model of material-drilling power. Moreover, the average accuracy of the improved material-drilling power model is up to $98.3 \%$, which is improved by $3.3 \%$ compared with the traditional empirical model. 


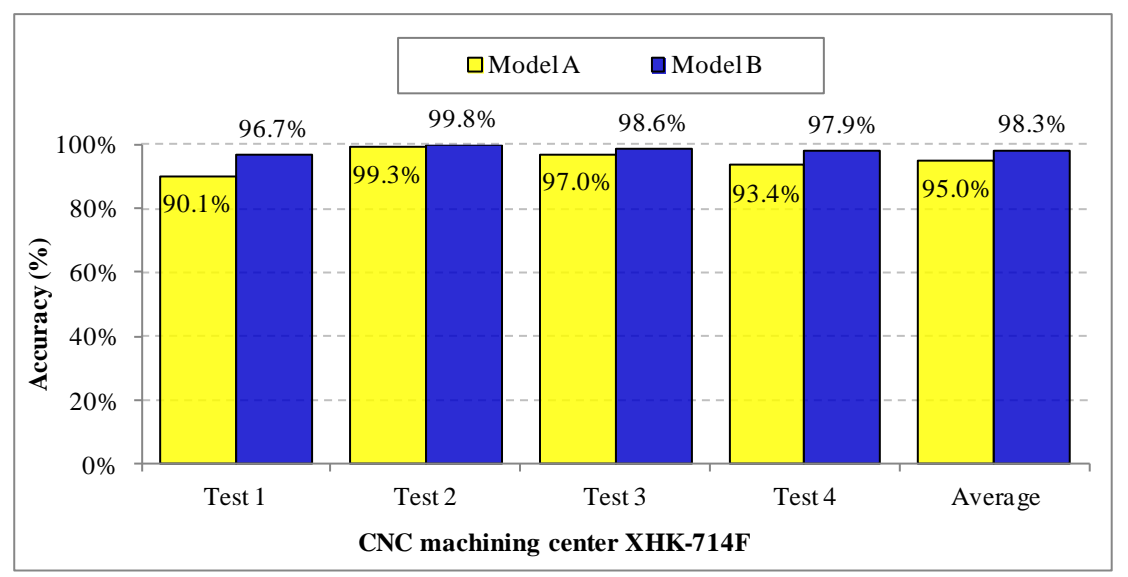

Figure 8. Comparison of accuracy of models A and B for XHK-714F CNC machining center.

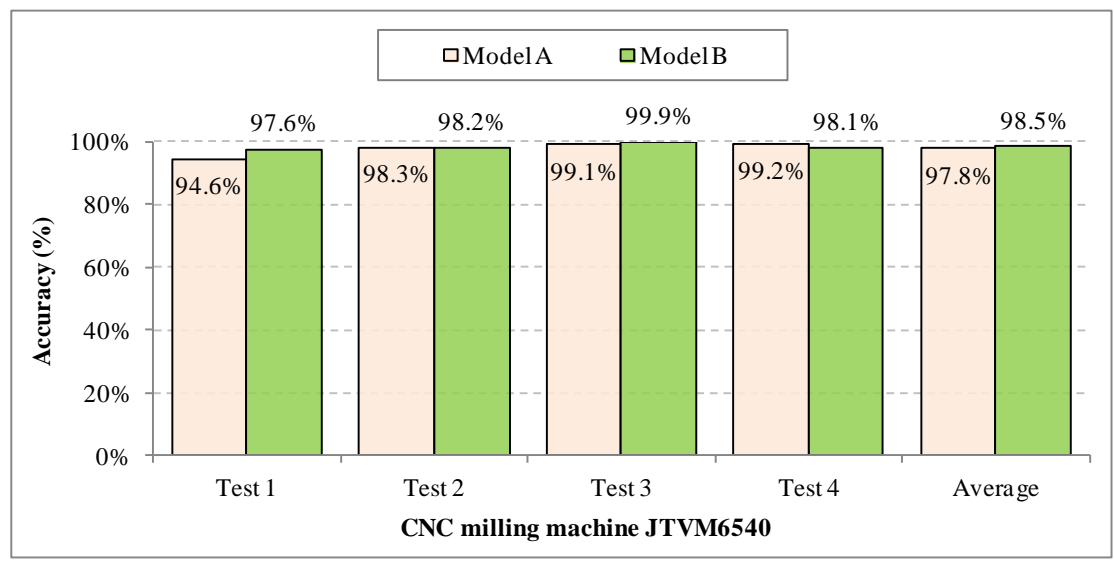

Figure 9. Comparison of accuracy of models A and B for JTVM6540 CNC milling machine.

As shown in Figure 9, the improved material-drilling power model (model B) can improve the prediction accuracy of the material-drilling power compared with the traditional empirical model of the material-drilling power (model B). It can be seen that the average accuracy of the improved material-drilling power model is up to $98.5 \%$, which is improved by $0.7 \%$ compared with the traditional empirical model. The results show that the prediction accuracy of the improved material-drilling power model established in this paper is significantly improved, generally higher than $96 \%$ for all the test experiments of the researched machine tools (XHK-714F CNC machining center and JTVM6540 CNC milling machine).

It can be seen that although the accuracy of the traditional empirical model is not low, it can further be improved by the improved material-drilling power model in this paper. The main reason is that the exponent of the spindle speed was assumed to be a fixed value (fixed to 1) in the traditional empirical model. However, this assumption is not very consistent with the exiting research result [51] and our previous experimental result showed in Figure 5. Actually, the influence of the drilling parameters (drill diameter $d$, feed rate $f$, and spindle speed $n$ ) on the material-drilling power are different. The different influence of each drilling parameter has been reflected in the improved material-drilling power model. The exponent of the spindle speed in the improved model is not a fixed value. Its value is affected by the cutting tool, workpiece material, and machine tool. That is to say, the value may be different under different combinations of cutting tools, workpiece materials, and machine tools. It can be drawn that the improved material-drilling power model is more reasonable and scientific compared with the traditional empirical model. The prediction accuracy can be expected to become better with the improved material-drilling power model. The experimental results also verify the above statement. 


\section{Conclusions}

Drilling process is some of the most widely used machining processes in the manufacturing industry. Establishing the accurate power model of the drilling process plays a significant role in manufacturing process energy modeling and energy savings. Material-drilling power is an important part of total drilling power, which is insufficiently researched. In this paper, the composition of the material-drilling power is studied firstly. Then, an improved material-drilling power model is established. Finally, experimental studies were carried out on a XHK-714F CNC machining center and JTVM6540 CNC milling machine. The results showed that the prediction accuracy of the improved material-drilling power model established in this paper is significantly improved, generally higher than $96 \%$ for all the test experiments. The average prediction accuracies of the improved material-drilling power are $98.3 \%$ and $98.5 \%$ for the XHK-714F CNC machining center and JTVM6540 CNC milling machine, respectively. Moreover, the prediction accuracy with the proposed model can be increased compared with the traditional empirical model, improvement of $3.3 \%$ and $0.7 \%$ can be achieved for the XHK-714F CNC machining center and JTVM6540 CNC milling machine. The power model proposed in this paper can provide a good foundation for energy modeling and optimization of drilling processes. Moreover, the establishment of a material-drilling power model can improve the transparency of energy consumption and help us to better understand the energy characteristics during drilling processes.

The differences and trends of the coefficients in the proposed model under different combinations of machine tools, cutting tools, and workpiece materials will be studied in our future research. Moreover, the material-drilling power is a crucial part of the total drilling power. With the proposed material-drilling power model, further research will be carried out to analyze and establish a prediction model of total drilling power, and then the energy optimization model of drilling processes will be researched.

Author Contributions: Q.Y. (Qinghe Yuan) and W.C. proposed the paper structure, S.J., J.L. and Z.Z. designed and performed the experiments. C.L. revised and improved the paper. S.J. and Q.Y. (Qingwen Yuan) conceived the paper, analyzed the data and wrote the paper.

Funding: This research was supported by the National Natural Science Foundation of China (Grant No. 71701113), Shandong Provincial Natural Science Foundation, China (Grant No. ZR2016GQ11, ZR2016EEP02), Project of Shandong Province Higher Educational Science and Technology Program (Grant No. J17KA167), and supported by SDUST Research Fund (Grant No. 2018YQJH103).

Acknowledgments: The authors sincerely thank editors and anonymous reviewers for their helpful suggestions on the quality improvement of our paper.

Conflicts of Interest: The authors declare no conflict of interest.

\section{References}

1. Solnørdal, M.; Foss, L. Closing the energy efficiency gap-A systematic review of empirical articles on drivers to energy efficiency in manufacturing firms. Energies 2018, 11, 518. [CrossRef]

2. Domingo, R.; Marín, M.; Claver, J.; Calvo, R. Selection of cutting inserts in dry machining for reducing energy consumption and $\mathrm{CO}_{2}$ emissions. Energies 2015, 8, 13081-13095. [CrossRef]

3. Energy Information Administration (EIA). International Energy Outlook 2017; U.S. Energy Information Administration: Washington, DC, USA, 2017; p. 76.

4. Salahi, N.; Jafari, M.A. Energy-performance as a driver for optimal production planning. Appl. Energy 2016, 174, 88-100. [CrossRef]

5. Cai, W.; Liu, F.; Xie, J.; Zhou, X. An energy management approach for the mechanical manufacturing industry through developing a multi-objective energy benchmark. Energy Convers. Manag. 2017, 132, 361-371. [CrossRef]

6. Gutowski, T.G.; Allwood, J.M.; Herrmann, C.; Sahni, S. A global assessment of manufacturing: Economic development, energy use, carbon emissions, and the potential for energy efficiency and materials recycling. Annu. Rev. Environ. Resour. 2013, 38, 81-106. [CrossRef] 
7. Hassan Khattak, S.; Oates, M.; Greenough, R. Towards improved energy and resource management in manufacturing. Energies 2018, 11, 1006. [CrossRef]

8. Campatelli, G.; Scippa, A.; Lorenzini, L.; Sato, R. Optimal workpiece orientation to reduce the energy consumption of a milling process. Int. J. Precis. Eng. Manuf.-Green Technol. 2015, 2, 5-13. [CrossRef]

9. Jia, S.; Tang, R.; Lv, J.; Yuan, Q.; Peng, T. Energy consumption modeling of machining transient states based on finite state machine. Int. J. Adv. Manuf. Technol. 2017, 88, 2305-2320. [CrossRef]

10. Gutowski, T. Energy and Environmental Issues for Manufacturing Processes. 2010. Available online: http:/ / web.mit.edu/2.810/www/lecture2011/Environment.pdf (accessed on 16 June 2017).

11. Liu, P.; Liu, F.; Qiu, H. A novel approach for acquiring the real-time energy efficiency of machine tools. Energy 2017, 121, 524-532. [CrossRef]

12. Jia, S.; Yuan, Q.; Lv, J.; Liu, Y.; Ren, D.; Zhang, Z. Therblig-Embedded value stream mapping method for lean energy machining. Energy 2017, 138, 1081-1098. [CrossRef]

13. Duflou, J.R.; Sutherland, J.W.; Dornfeld, D.; Herrmann, C.; Jeswiet, J.; Kara, S.; Hauschild, M.; Kellens, K. Towards energy and resource efficient manufacturing: A processes and systems approach. CIRP. Ann.-Manuf. Technol. 2012, 61, 587-609. [CrossRef]

14. Jia, S.; Yuan, Q.; Cai, W.; Li, M.; Li, Z. Energy modeling method of machine-operator system for sustainable machining. Energy Convers. Manag. 2018, 172, 265-276. [CrossRef]

15. Zhou, L.; Li, J.; Li, F.; Xu, X.; Wang, L.; Wang, G.; Kong, L. An improved cutting power model of machine tools in milling process. Int. J. Adv. Manuf. Technol. 2017, 91, 2383-2420. [CrossRef]

16. Luan, X.; Zhang, S.; Chen, J.; Li, G. Energy modelling and energy saving strategy analysis of a machine tool during non-cutting status. Int. J. Prod. Res. 2017, 56, 1-17. [CrossRef]

17. Li, W.; Winter, M.; Kara, S.; Herrmann, C. Eco-efficiency of manufacturing processes: A grinding case. CIRP Ann.-Manuf. Technol. 2012, 61, 59-62. [CrossRef]

18. Amran, M.A.; Salmah, S.; Hussein, N.I.S.; Izamshah, R.; Hadzley, M.; Sivaraos; Kasim, M.S.; Sulaiman, M.A. Effects of machine parameters on surface roughness using response surface method in drilling process. Procedia Eng. 2013, 68, 24-29. [CrossRef]

19. Jia, S. Research on Energy Demand Modeling and Intelligent Computing of Machining Process for Low Carbon Manufacturing; Zhejiang University: Hangzhou, China, 2014.

20. Jia, S.; Tang, R.; Lv, J. Therblig-based energy demand modeling methodology of machining process to support intelligent manufacturing. J. Intell. Manuf. 2014, 25, 913-931. [CrossRef]

21. Hu, L.; Peng, T.; Peng, C.; Tang, R. Energy consumption monitoring for the order fulfillment in a ubiquitous manufacturing environment. Int. J. Adv. Manuf. Technol. 2017, 89, 3087-3100. [CrossRef]

22. Gontarz, A.M.; Hampl, D.; Weiss, L.; Wegener, K. Resource consumption monitoring in manufacturing environments. Procedia CIRP 2015, 26, 264-269. [CrossRef]

23. Bogdanski, G.; Spiering, T.; Li, W.; Herrmann, C.; Kara, S. Energy monitoring in manufacturing companies-Generating energy awareness through feedback. In Proceedings of the 19th CIRP International Conference on Life Cycle Engineering, Berkeley, CA, USA, 23-25 May 2012.

24. Schmidt, C.; Li, W.; Thiede, S.; Kara, S.; Herrmann, C. A methodology for customized prediction of energy consumption in manufacturing industries. Int. J. Precis. Eng. Manuf.-Green Teshnol. 2015, 2, 163-172. [CrossRef]

25. Lee, W.; Lee, C.-Y.; Mi, B.-K. Simulation-based energy usage profiling of machine tool at the component level. Int. J. Precis. Eng. Manuf.-Green Technol. 2014, 3, 183-189. [CrossRef]

26. Akbostanc1, E.; Tunç, G.I.; Türüt-Aşık, S. $\mathrm{CO}_{2}$ emissions of Turkish manufacturing industry: A decomposition analysis. Appl. Energy 2011, 88, 2273-2278. [CrossRef]

27. Feng, L.; Mears, L.; Beaufort, C.; Schulte, J. Energy, economy, and environment analysis and optimization on manufacturing plant energy supply system. Energy Convers. Manag. 2016, 117, 454-465. [CrossRef]

28. Yi, Q.; Li, C.; Tang, Y.; Chen, X. Multi-objective parameter optimization of CNC machining for low carbon manufacturing. J. Clean. Prod. 2015, 95, 256-264. [CrossRef]

29. Lv, J.; Tang, R.; Tang, W.; Liu, Y.; Zhang, Y.; Jia, S. An investigation into reducing the spindle acceleration energy consumption of machine tools. J. Clean. Prod. 2017, 143, 794-803. [CrossRef]

30. Önüt, S.; Soner, S. Analysis of energy use and efficiency in Turkish manufacturing sector SMEs. Energy Convers. Manag. 2007, 48, 384-394. [CrossRef] 
31. Cai, W.; Liu, F.; Dinolov, O.; Xie, J.; Liu, P.; Tuo, J. Energy benchmarking rules in machining systems. Energy 2018, 142, 258-263. [CrossRef]

32. Chan, D.Y.-L.; Huang, C.-F.; Lin, W.-C.; Hong, G.-B. Energy efficiency benchmarking of energy-intensive industries in Taiwan. Energy Convers. Manag. 2014, 77, 216-220. [CrossRef]

33. Cai, W.; Liu, C.; Zhang, C.; Ma, M.; Rao, W.; Li, W.; He, K.; Gao, M. Developing the ecological compensation criterion of industrial solid waste based on emergy for sustainable development. Energy 2018, 157, 940-948. [CrossRef]

34. Cai, W.; Liu, F.; Zhou, X.; Xie, J. Fine energy consumption allowance of workpieces in the mechanical manufacturing industry. Energy 2016, 114, 623-633. [CrossRef]

35. Jia, S.; Tang, R.; Lv, J.; Zhang, Z.; Yuan, Q. Energy modeling for variable material removal rate machining process: An end face turning case. Int. J. Adv. Manuf. Technol. 2016, 85, 2805-2818. [CrossRef]

36. Jia, S.; Yuan, Q.; Ren, D.; Lv, J. Energy demand modeling methodology of key state transitions of turning processes. Energies 2017, 10, 462. [CrossRef]

37. Tristo, G.; Bissacco, G.; Lebar, A.; Valentinčič, J. Real time power consumption monitoring for energy efficiency analysis in micro EDM milling. Int. J. Adv. Manuf. Technol. 2015, 78, 1511-1521. [CrossRef]

38. Ma, F.; Zhang, H.; Cao, H.; Hon, K.K.B. An energy consumption optimization strategy for CNC milling. Int. J. Adv. Manuf. Technol. 2017, 90, 1715-1726. [CrossRef]

39. Li, C.; Chen, X.; Tang, Y.; Li, L. Selection of optimum parameters in multi-pass face milling for maximum energy efficiency and minimum production cost. J. Clean. Prod. 2017, 140, 1805-1818. [CrossRef]

40. Albertelli, P.; Keshari, A.; Matta, A. Energy oriented multi cutting parameter optimization in face milling. J. Clean. Prod. 2016, 137, 1602-1618. [CrossRef]

41. Murray, V.R.; Zhao, F.; Sutherland, J.W. Life cycle analysis of grinding: A case study of non-cylindrical computer numerical control grinding via a unit-process life cycle inventory approach. Proc. Inst. Mech. Eng. Part B 2012, 226, 1604-1611. [CrossRef]

42. Priarone, P.C. Quality-conscious optimization of energy consumption in a grinding process applying sustainability indicators. Int. J. Adv. Manuf. Technol. 2016, 86, 2107-2117. [CrossRef]

43. Zheng, J.; Huang, B.; Zhou, X. A low carbon process design method of sand casting based on process design parameters. J. Clean. Prod. 2018, 197, 1408-1422. [CrossRef]

44. Yoon, H.S.; Moon, J.S.; Pham, M.Q.; Lee, G.B.; Ahn, S.H. Control of machining parameters for energy and cost savings in micro-scale drilling of PCBs. J. Clean. Prod. 2013, 54, 41-48. [CrossRef]

45. Franco, A.; Rashed, C.A.A.; Romoli, L. Analysis of energy consumption in micro-drilling processes. J. Clean. Prod. 2016, 137, 1260-1269. [CrossRef]

46. Yoon, H.S.; Bhandari, B.; Moon, J.S.; Kim, C.S.; Lee, G.B.; Park, K.W.; Song, C.K.; Ahn, S.H. Energy analysis of micro-drilling process used to manufacture printed circuit boards. In Proceedings of the 19th CIRP International Conference on Life Cycle Engineering, Berkeley, CA, USA, 23-25 May 2012.

47. Gutowski, T.; Dahmus, J.; Thiriez, A. Electrical energy requirements for manufacturing processes. In Proceedings of the 13th CIRP International Conference on Life Cycle Engineering, Leuven, Belgium, 31 May-2 June 2006.

48. Ai, X.; Xiao, S. Manual of Cutting Parameters, 3rd ed.; China Machine Press: Beijing, China, 1994.

49. Wang, X. Manual of Machining Process (Offprint): Drilling, Expanding, and Reaming; China Machine Press: Beijing, China, 2008.

50. Tuo, J.; Liu, F.; Liu, P.; Zhang, H.; Cai, W. Energy efficiency evaluation for machining systems through virtual part. Energy 2018, 159, 172-183. [CrossRef]

51. Yang, L.; Xu, L. Experimental research on drilling power for high manganese steel based on new improved drill tool. Mach. Tool Hydraul. 2010, 38, 29-31.

(C) 2018 by the authors. Licensee MDPI, Basel, Switzerland. This article is an open access article distributed under the terms and conditions of the Creative Commons Attribution (CC BY) license (http://creativecommons.org/licenses/by/4.0/). 